\title{
Martha Bracho: Honor a quien honor merece ${ }^{1}$
}

Evangelina Osio

Ahí está. Su silueta esbelta recorta el espacio del enorme salón de danza del Museo y Biblioteca. Los cabellos cortos, el rostro afinado, los pómulos altos, la presencia distinguida. La encuentro en su escritorio organizando, ordenando papeles con sus manos de yadró. Esas manos que no se detienen. Alas. Con sus uñas siempre largas, rojas, su eterna media luna "para que respiren".

¡Dios mío! Que fortaleza de mujer. Todos los poros de su piel destilan solvencia. No puedo ser parca. Mi infancia y juventud fueron impactadas con su serena pero recia personalidad: Bailarina de sólida formación, maestra rigurosa, coreógrafa prolífica. Sin embargo, si tuviera que nombrarla con una sola palabra, no lo dudaría: Una dama.

Hay seres que la existencia engarruña y empequeñece, no pueden con ella y se arrinconan, se van enjutando, endureciendo como nueces. En cambio, ella ha domesticado al desierto, a la vida y ha sabido hacerlo creativamente.

Es la disciplina misma. Y todos los días, todas las mañanas al levantarse cosecha a cielo abierto lo que ha sembrado. Muchos años de tenacidad y laboriosa existencia no le han restado vitalidad a su madurez.

No necesita presentación, ha esparcido el vuelo de su danza por todo Sonora y es ampliamente reconocida por el gremio dancístico nacional. Pero para quien lo desconozca, se llama Martha Bracho Torres y radica en Hermosillo desde 1954.
Increíble es la trayectoria de Martha. Cuando llega a Sonora "...era una luminaria del movimiento mexicano de danza moderna. Había desempeñado papeles importantísimos en el Palacio de Bellas Artes." (1) Maestra titulada como profesora de danza en el Conservatorio Nacional. Bailarina fundadora y coreógrafa de La Paloma Azul, compañía que dirige la norteamericana Anna Sokolow, grupo que marca un antes y un después en el movimiento dancístico nacional.

Egresada de la Escuela Nacional de Danza, maestra y coreógrafa de la Academia de la Danza Mexicana. Alumna de personalidades como José Limón, Doris Humprey y Lucas Hoving. Cuando se encontraba en la cúspide de su carrera que apuntaba cada vez más hacia la cima, recibe la invitación de la Universidad de Sonora.

La academia de Danza de la Universidad de Sonora, fue fundada en 1954, por la iniciativa del ingeniero Norberto Aguirre Palancares, entonces Rector de dicha Universidad. En enrevista con Alberto Dallal, reconocido investigador y crítico, Martha Bracho comenta:

...cuando llegué allí, el Estado era un campo virgen para la danza, muy cerrado. Las personas eran muy especiales en sus costumbres y en sus conceptos sobre la moralidad. Las muchachas que querían estudiar danza conmigo ya me lo habían confesado. Entonces les dije: Vengan a tomar la clase con pantalones, porque hubiera sido imposible pedirles mallas o payasos. Las vi entrar el primer día, pero con vestidos. ¿Dónde

${ }^{1}$ Entrevista publicada en el periódico el Imparcial. Sección Perfiles. Hermosillo, Sonora, Junio 1997. 
están los pantalones? Pregunte. Aquí, dijeron: debajo de los vestidos. Pero, como...pues quítense el vestido. No, exclamaron a coro, porque nuestros papás no nos dejan... ${ }^{(2)}$

Una verdadera proeza. A cuarenta y cuatro años de distancia la Bracho ha recibido múltiples reconocimientos y homenajes. En 1993 el rector de la UNISON, Jorge Luis Ibarra, le otorgó el título de Maestra Emérita, la distinción más alta que nuestra Alma Mater concede.

Sin embargo, tengo la certeza de que la satisfacción más grande para la profesora, como la llamamos cariñosamente, es la de impartir día a día sus clases, el contacto permanente con los alumnos. Cientos de cientos de niñas y jóvenes han pasado por sus aulas. Maestra de maestras.

El presente la envuelve, intuyo que le cuesta trabajo mirar hacia el pasado. No corre el riesgo de convertirse en estatua de sal. No hay tiempo para la especulación. Su vida gira sobre la danza del presente día. Hoy, sin embargo, le pido a Martha Bracho que vaya atrás, que recuerde, recuerde, recuerde.

\section{Los primeros pasos}

Mi primera maestra fue Linda Costa, nos daba clases de baile en la escuela de educación pública, y vio que tenía aptitudes. No recuerdo si me encontraba en cuarto o quinto grado. Fue ella la que me entusiasmó para que entrara a la escuela de danza que estaba en la Secretaría de Educación Pública. Fue así como pasé a ser alumna de Hipólito Zybine.

\section{Apoyo Familiar}

En relación a tu pregunta de que si mis padres o parientes veían con buenos o malos ojos que me dedicara a la danza, tuve suerte de tener todo el apoyo. Recuerdo que tiempo después, cuando llegué a la Escuela de Bellas Artes que se encontraba en el Palacio mismo, había una salita donde las madres y las hermanas nos esperaban. Mi hermana Lola siempre me llevó. Por años fue mi acompañante y con muchísima paciencia esperó sentada mientras tomaba mis clases.

\section{La danza y el juego, una misma actividad}

-Profesora, ¿tuvo tiempo para jugar?

...Yo creo que no - Sonríe - y no me hacía falta, bueno, supongo que en sábados y domingos...

-¿Desde niña pensó que esa iba a ser su profesión?

No a esa edad (9 años). Me encantaba, me encantaba, era un juego que me fascinaba. Además del ballet cursaba bailes mexicanos, danza oriental, tap y acrobático; baile español, danza moderna y música. Por otro lado, tomaba además clases de canto.

\section{Los Bracho: tronco familiar de sólida cepa artística}

De la familia de mi mamá tuve una tía, la famosísima Fany Anitúa, ella nació en Durango de donde desciende la familia materna. La tía Fany, siendo muy joven recibió una beca para ir a estudiar a la Scala de Milán. Y por parte de los Bracho, hay muchos actores y directores. Julio Bracho es mi primo, su hija Diana es actriz. Chucho (Bracho) el escultor y muchos otros artistas en diferentes ramas del arte.

\section{Alumna de maestros y maestra de maes- tras}

Cuando en 1939 llega Anna Sokolow a México, pionera indiscutible del movimiento mexicano de danza moderna, se integra al movimiento que ya la pintura, la música y las artes plásticas habían abierto brecha en el aire contemporáneo. Sokolow, judía norteamericana de ascendencia rusa, reúne a un grupo de bailarines entre los que se encontraban Raquel, Carmen e Isabel Gutiérrez, Ana Mérida, Rosa Reyna, Esthela Garfias y Martha Bracho, entre otros. A La Paloma azul se le incorporan algunos creadores notables como Blas Galindo, Rodolfo Halfter, Manuel Rodríguez Lozano y otros, La época de Oro de la Danza Mexicana iniciaba.

-Martha, ¿Qué significó para usted formar parte de "las Sokolowas" como las ha registrado la historia?

Fue una etapa importantísima. Me permitió desarrollarme en la danza profesionalmente. Por otro lado, me inicié como 
coreógrafa. Se trataba de un grupo muy armonioso, Rosa Reyna por ejemplo, quien sigue siendo una amiga muy querida. En ese entonces fue fundamental el apoyo e funcionarios tan importantes como Vasconcelos, Carlos Chávez y Gorostiza; músicos como Revueltas, Blas Galindo; escenógrafos, literatos y pintores de la talla de Rodríguez Lozano, colaboraban en la creación de las obra que presentábamos en Bellas Artes.

\section{El maestro ruso Hipólito Zybine}

-Maestra, ¿quién fue la persona que más influencia tuvo en su formación?

Hipólito Zybine. En sus clases de ballet me sentía realizada. Considero que él me formó y me dio las bases.

- ¿Le hubiera gustado ser bailarina clásica? Puede ser que en esa etapa sí, pero ya después, cuando conocí la danza moderna fue otra cosa. La verdad es que tenía pies muy fuertes y el tipo de piernas que se requieren. (Sonríe, la siento muy lejos)... era espléndido [Zybine] fue como un papá. Recuerdo el entrenamiento tan intenso al que nos sometía a la hora de realizar los "fuetés". Yo hacía no solamente los treinta y dos, llegaba a girar hasta treinta y seis, treinta y siete, cuarenta...(Martha regresa del pasado) ¡Que época! exclama.

\section{Miguel Covarrubias, impulsor de las artes}

- ¿Recuerda usted a Covarrubias?

Claro, además de ser un gran artista, fue un promotor importantísimo en la vida cultural del país. Yo me encontraba en la Academia de la Danza Mexicana cuando él era director. Era una persona muy amable, muy linda. Fue a él a quién se dirigió el ingeniero Norberto Aguirre Palancares para solicitarle una maestra de danza para la Universidad de Sonora.

\section{Febrero 9 de 1954, un nuevo destino}

-Un día de Febrero del año cincuenta y cuatro, la joven Bracho toma el avión hacia algún lugar del norte. No sabía a ciencia cierta hacia dónde volaba. Tampoco podía imaginar que se encontraba en el umbral de una nueva vida. El 9 de febrero pisa tierra sonorense. Son los primeros pasos de la danza moderna en el Estado. Es el principio.

-¿Qué le atrajo de Hermosillo, por qué se quedó en esta ciudad, dejando el bullicio y efervescencia donde usted jugaba un papel protagónico?

Me lo he preguntado muchas veces. Creo que en primer lugar era un reto, el ingeniero Aguirre Palancares le solicitó a Gorostiza, entonces Director de Bellas Artes, una maestra de danza para que impartiera un curso de tres meses. Se trataba de darle a las chicas, una actividad artística y física. No fue a mí a quien llamaron. Carlos Chávez, por instrucciones de Gorostiza, extendió la invitación a Rosa Reyna, pero ella no podía; Raquel Gutiérrez, tampoco, y la verdad es que así fue como llegó a mí la invitación. A nosotras, nos llamaban "las Sokolowas", nos consideraban las bailarinas fuertes de La Paloma Azul.

En ese momento estábamos terminando una temporada en Bellas Artes, y nos encontrábamos únicamente en clases, y pensé que no perdía nada con ir a conocer y dar un curso de Febrero a Abril.

-¿Sabía usted dónde estaba Hermosillo?

No, no, ni idea.

-¿Consultó un mapa?

No - sonríe -

Y empecé, y ya sabes tú las dificultades que tuve al inicio: el desconocimiento, la escuela de las madres que prohibían el payaso y la danza. Pero con mucha satisfacción recuerdo que a los tres o cuatro meses de estar dando clases, vino el director de Bellas Artes y pude hacer una demostración del trabajo hecho con las muchachas. Ese fue el principio...y creo que voy a terminar aquí.

\section{Una posible cantante}

-Si usted no hubiera sido bailarina, ¿qué le hubiera gustado ser?

Fíjate que tenía bastante buena voz. En una ocasión que vino mi tía Fany (Anitúa), ella regresaba de Italia, siendo ya una cantante renombrada, mi mamá la invitó a mis clases de canto para que me escuchara, ¡Ya sabes cómo son las mamás! Recuerdo que canté un aria breve. Me quería llevar 
con ella a Italia, y no tenía mala voz (se ríe), pero me dijo: "O cantas o bailas, con las dos cosas no puedes". Conoces mi respuesta.

\section{Licenciatura en danza}

-¿Qué opina del nuevo programa que próximamente se abrirá en el Centro de las Artes?

¡Magnífico, magnífico!, por supuesto. Mis compañeras y yo tuvimos la fortuna de tener durante años una carrera con muchos y muy buenos maestros. Esta nueva oportunidad que se abre a los jóvenes es muy importante.

\section{¿Y del amor...?}

Dar amor es maravilloso. Yo he dado y siento que lo doy a mis alumnas, a través de mis clases, al transmitirles lo que yo amo y conozco. De alguna manera es una relación de maestra y de madre. Me siento muy ligada a ellas.

Coreógrafa prolífica. Alrededor de cincuenta obras

-En 1949 Martha Bracho se inicia como coreógrafa, en la temporada del ballet mexicano en el Palacio de Bellas Artes, junto con Rosa Reyna compone "Suite" con música de Scarlatti. Ese mismo año es invitada a montar las danzas de "La Traviata" para la temporada de ópera nacional.

-La nueva coreógrafa comprendió a tiempo que lo moderno no es un estilo, es una tendencia. De ahí que en sus creaciones se fueron apreciando recursos constantemente diferentes.

- En sus danzas plasma sus influencias y gustos: El ballet, la presencia nacionalista, el folklore español, las danzas mexicanas. El saldo: alrededor de cincuenta piezas, legado de una vida regida por la creatividad, trabajo, trabajo, y más trabajo.

"Huapango" (1959), "El Renacuajo paseador" (1960), "Cuatro Sonatas de Scarlati" (1955), "Sensemayá" (1961), "La Visita" (1961), "Bach en ritmo de Jazz" (1966), "Idilio Yaqui" (1957), "Siempre Habrá una Esperanza" (1982), entre muchas otras.
-Profesora, de sus obras, ¿Cuál es su preferida?

"Variaciones" con La Valse (1962) de Ravel, me gusta mucho. Otra de mis preferidas es "Bolero" (1963), también con música de Ravel.

No pienso en la muerte, me importa la vida.

-¿Le teme a la muerte?, ¿qué cree que hay más allá?

No, no sé (esboza una sonrisa). No pienso en ella, me importa la vida. Ojalá que hubiera lo que yo he hecho siempre: Danza. Será que tengo buena salud, buen trabajo y muchas satisfacciones.

\section{Danza: movimientos agradables y bellos} -En relación a lo que vimos en el reciente festival "Un Desierto para la Danza", ¿Qué opina? Suave pero firme, responde: Hubo coreografías que para mí no eran danza, vi poca, aunque con excepciones, en algunas de las presentaciones me salí. Para mí la danza tiene que tener movimientos agradables, elegantes, que expresen algo, que te lleguen. Debe tener giros, saltos, movimientos de brazos y una serie de expresiones que te saquen de ti mismo, y no aquellas cosas estáticas, repetitivas, $o$ en columpios...No, no. Parece que si uno no entra en esa corriente, te quedas atrás, pero yo creo que nunca podría hacer algo así.

\section{El sueño de Martha Bracho}

-Una última pregunta, si un hada buena llegara con su varita mágica y le dijera ¿Qué deseo quieres que se te convierta realidad? ¿Qué le pediría usted? Silencio. Martha Bracho se queda inmóvil, sólo sus ojos se clavan en mí. Y tomando aire responde:

La oportunidad de seguir formando muchachas, de verlas convertirse en buenas bailarinas o en maestras. Así que ¡Hada buena concédemelo! ¡Qué más puedo pedir!

Evangelina Osio es antropóloga por la ENAH, critica de danza; ha sido bailarina profesional, $y$ promotora cultural.

(1) Dallal, Alberto: La Danza en México, primera parte; UNAM, Seg. Ed. 1995; México D.F. p. 207.

(2) Dallal, Alberto, La Danza en México, primera parte; UNAM, Seg. Ed. 1995; México D.F. pp 207, 208. (Entrevista a Martha Bracho) 